\title{
MicroRNA-196b Inhibits Cell Growth and Metastasis of Lung Cancer Cells by Targeting Runx2
}

\author{
Xiaoxue Bai ${ }^{a}$ Lin Meng ${ }^{a}$ Huijie Sun ${ }^{a}$ Zhuo Li ${ }^{b} \quad$ Xiufang Zhang \\ Shucheng Huac
}

${ }^{a}$ Cadre's Ward, The First Hospital of Jilin University, Changchun, bepartment of Endocrinology, The First Hospital of Jilin University, Changchun, 'Department of Respiratory Medicine, The First Hospital of Jilin University, Changchun, China

\section{Key Words}

MiR-196b • Lung cancer • Runx2 • PI3K/AKT/GSK3 $\beta$ pathway • Smad pathway • JNK pathway

\begin{abstract}
Background/Aims: Lung cancer is one of the most common causes of cancer related deaths worldwide. The role of several microRNAs (miRNAs) including miR-196b in different cancers has already been established. The study was aimed to explore the role of miR-196b in lung cancer and its possible underlying mechanism. Methods: Human lung cancer cell line A549 was transfected with miR-196b mimic, miR-196b inhibitor and corresponding controls. Then cell viability, migration, invasion, and apoptosis of A549 lung cancer cells either with overexpression or with suppression of miR-196b were estimated sequentially. Next, dual luciferase activity assay was performed to clarify whether Runx2 was a direct target of miR-196b. Finally, the expressions of main factors associated with epithelial mesenchymal transition (EMT), PI3K/ AKT/GSK3 3 , Smad, and JNK pathways were detected by western blot. Results: MiR-196b expression was significantly decreased in A549, H1650 and $\mathrm{H} 1299$ cell lines compared with in WI-38 and HEL-1 cell lines. Overexpression of miR-196b suppressed cell viability, migration, invasion, and induced apoptosis as well as inhibited TGF- $\beta$ induced EMT process in A549 cells. In addition, Runx 2 was a putative target of miR-196b, and Runx2 silence remarkably increased cell apoptosis and abolished the promotive effects of miR-196b suppression on cell viability, migration and invasion. Finally, miR-196b also mediated its action by inactivation of PI3K/ AKT/GSK3 3 , Smad, and JNK pathways by down-regulation of Runx2. Conclusion: MiR-196b functions as a tumor suppressor that inhibited cell growth and metastasis of lung cancer cells by targeting Runx2. These findings provided further evidences for treatment of lung cancer.
\end{abstract}

\section{Introduction}

(C) 2017 The Author(s)

Published by S. Karger AG, Basel

Lung cancer is one of the most common malignancies and remains the leading cause of cancer-related deaths worldwide [1]. In the various histological subtypes, non-small cell

Shucheng Hua

KARGER
Department of Respiratory Medicine, The First Hospital of Jilin University,

No. 71, Xinmin Street, Changchun 130021 (China)

E-Mail shuchenghua@eyou.com 


\section{Cellular Physiology Cell Physiol Biochem 2017;43:757-767

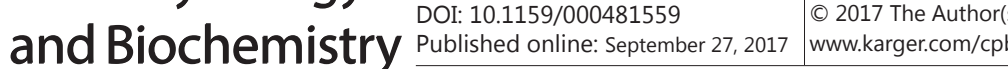 \\ Bai et al.: Role of Mir-196b in Lung Cancer by Targeting Runx2}

lung cancer (NSCLC) is the most prevalent subtype, which accounts for approximately $80 \%$ in all cases of diagnosed with lung cancer $[1,2]$. NSCLC is characterized by a high mortality, and the overall five-year survival rate remains less than 15\% [2]. Seriously, most of the patients are diagnosed in the latest stage of lung cancer, especially in stage IV [3]. Despite the different therapeutic methods such as chemotherapy, radiotherapy, and surgery were utilized to improve the survival rate of patients with lung cancer, the inevitable metastasis remain a great challenge for the treatment of lung cancer $[4,5]$. Hence, there is an urgent need to introduce novel and effective therapies for treating lung cancer.

MicroRNAs (miRNAs or miRs) are a small class of single-stranded and non-coding RNAs, which are participated in post-transcriptional regulation of more than $70 \%$ human genes expression [5, 6]. Accumulating evidences indicated that miRNAs play crucial roles in a wide range of cellular biological processes, including cell division, proliferation, differentiation, metastasis and apoptosis of various cancers $[7,8]$. In the studies of lung cancer, Yan et al. demonstrated that miR-761 promoted cell proliferation and metastasis of NSCLC by targeting ING4 and TIMP2 [9]. In addition, Jiang et al. revealed that miR-21 suppressed the proliferation and migration of lung cancer A549 cells [10]. Although miRNAs were involved in the development, progression and metastasis of lung cancer, the effect of miR-196b on lung cancer was not straightforward [11].

MiR-196b is a member of miR-196 family, which has been validated as tumor suppressor in various cancers $[12,13]$. As Rebucci et al. displayed that miR-196b as a tumor suppressor that suppressed cell proliferation and induced apoptosis in HepG2 cells [13]. Moreover, Bhatia et al. also found that the role of miR-196b as tumor suppressor in blood cancers $[14,15]$. In lung cancer, recent studies showed that miR-196b promoted cell invasion and induced epithelial mesenchymal transition (EMT) process in NSCLC cells [1, 16]. Simultaneously, Tellez et al. found that miR-196b as a tumor suppressor whose silencing early in lung carcinogenesis might provide a selective growth advantage to pre-malignant cells [17]. However, the detail roles of miR-196b in lung cancer cells proliferation, metastasis and apoptosis have not been investigated.

Runt-related transcription factor 2 (Runx2) belongs to the Runx family, which is known to be an important regulator of organogenesis and cell differentiation [18]. Abnormal expressions of Runx genes are associated with variety of cancers, especially breast and osteosarcoma $[18,19]$. Moreover, the effect of Runx2 on lung cancer has also been explored in several studies [20-22]. However, whether Runx2 acted as a key regulator in lung cancer cells proliferation, metastasis and apoptosis remain unclear.

In this study, we aimed to explore the effect of miR-196b in lung cancer. Firstly, we examined the expressions of miR-196b in lung cancer cell lines and normal lung cell lines. Then we used CCK-8, Transwell, flow cytometry assays to analyze A549 cells viability, migration, invasion and apoptosis. Lastly, the key factors expressions of apoptosis, EMT, phosphatidylinositol 3 kinase (PI3K)/protein kinase B (AKT)/ glycogen synthase kinase 3 beta (GSK3 $\beta$ ), Smad, and Jun N-terminal kinases (JNK) pathways were detected by western blot. Our study will provide a new idea and theoretical basis for treatment of lung cancer.

\section{Materials and Methods}

\section{Cell culture and treatment}

Human lung cancer cell lines A549, H1650 and H1299 cells and human lung cell lines WI-38 and HEL1 cells were purchased from American Type Culture Collection (ATCC, Manassas, VA). All these cells were maintained in Roswell Park Memorial Institute (RPMI) 1640 medium supplemented with 1× antibioticantimycotic mixture (Gibco, Grand Island, NY) and 10\% fetal bovine serum (FBS, Hyclone Laboratories, Logan, UT) at $37^{\circ} \mathrm{C}$ in an atmosphere of $5 \% \mathrm{CO}_{2}-95 \%$ air. Transforming growth factor-beta 1 (TGF- $\beta 1,10$ $\mathrm{ng} / \mathrm{ml}$ ) was used to induce EMT. 


\section{Cellular Physiology Cell Physiol Biochem 2017;43:757-767 \begin{tabular}{l|l|l} 
and Biochemistry Published online: September 27, 2017 & $\begin{array}{l}\text { (0) 2017 The Author(s). Published by S. Karger AG, Basel } \\
\text { www.karger.com/cpb }\end{array}$ \\
\hline
\end{tabular}}

Bai et al.: Role of Mir-196b in Lung Cancer by Targeting Runx2

\section{Cell transfection}

MiR-196b mimic, miR-196b inhibitor and corresponding controls were synthesized by GenePharma Co. (Shanghai, China). In addition, Runx2 targeted small interfering RNA (si-Runx2) was also constructed by GenePharma Co. (Shanghai) to inhibit Runx2 expression. In brief, $1 \times 10^{5}$ cells were cultured in 6-well plate and all transfection cells were accomplished using Lipofectamine 3000 reagent (Invitrogen) following the manufacturer's protocol.

\section{Cell viability assay}

Cells were seeded in 96-well plate with 5000 cells/well, and cell viability was assessed by a Cell Counting Kit-8 (CCK-8, Dojindo Molecular Technologies, Gaithersburg, MD). Briefly, after transfection for $48 \mathrm{~h}$, the $10 \mu \mathrm{l} \mathrm{CCK-8} \mathrm{solution} \mathrm{was} \mathrm{added} \mathrm{to} \mathrm{the} \mathrm{culture} \mathrm{medium,} \mathrm{and} \mathrm{the} \mathrm{cultures} \mathrm{were} \mathrm{incubated} \mathrm{for} 1 \mathrm{~h}$ at $37^{\circ} \mathrm{C}$ in humidified $95 \%$ air and $5 \% \mathrm{CO}_{2}$. The absorbance was measured at $450 \mathrm{~nm}$ using a Microplate Reader (Bio-Rad, Hercules, CA).

\section{Migration and invasion assay}

Cell migration and invasion assays were determined by using a modified two-chamber chambers with a pore size of $8 \mathrm{~mm}$. For migration assay, cells suspended in $200 \mu \mathrm{l}$ of serum-free medium were seeded on the upper compartment of 24-well Transwell culture chamber, and $600 \mu \mathrm{l}$ of complete medium was added to the lower compartment. After incubation for $48 \mathrm{~h}$ at $37^{\circ} \mathrm{C}$, cells were fixed with methanol. Non-traversed cells were removed from the upper surface of the filter carefully with a cotton swab. Traversed cells on the lower side of the filter were stained with $0.1 \%$ crystal violet (Merck, Darmstadt, Germany) and counted. For invasion assay, the invasion capacity detection was conducted the same as migration assay, except utilizing Matrigel coated inserts with $8 \mathrm{~mm}$ pore size (catalog no. 354480, BD Biosciences) [23].

\section{Apoptosis assay}

Cell apoptosis was quantified with a flow cytometry using propidium iodide (PI) and fluorescein isothiocynate (FITC)-conjugated Annexin V staining (Beyotime Biotechnology). Briefly, cells were washed three times in phosphate buffered saline (PBS) and then were re-suspended in the staining buffer. Subsequently, $10 \mu \mathrm{l}$ FITC-Annexin V $(20 \mu \mathrm{g} / \mathrm{ml})$ and $5 \mu \mathrm{l} \mathrm{PI}(50 \mu \mathrm{g} / \mathrm{ml})$ were mixed with these cells. After incubation for $10 \mathrm{~min}$ in a dark at room temperature, the mixtures were examined using the FACS can flow cytometry system (Beckman Coulter, Fullerton, CA, USA). The data were analyzed by using FlowJo software (Tree Star, Inc., Ashland, OR, USA).

\section{qRT-PCR}

Total RNA was extracted from cells using Trizol reagent (Life Technologies Corporation, Carlsbad, CA, USA) according to the manufacturer's instructions. Then the first-strand complementary DNAs (cDNAs) were synthesized using $1 \mu \mathrm{g}$ RNAs by PrimeScript 1st Strand cDNA Synthesis Kit (TaKaRa Bio, Siga, Japan). The One Step SYBR® PrimeScript ${ }^{\circledR} P L U S$ RT-RNA PCR Kit (TaKaRa) was used for the Real-Time PCR analysis to test the expression levels of miR-196b in cells. U6 RNA was used to normalize the miR-196b levels and GAPDH was used to normalize other mRNAs levels. Data were analyzed with the $2^{-\Delta \Delta C t}$ method.

\section{Dual luciferase activity assay}

The 3'UTR target site was generated by PCR and the luciferase reporter constructs with the Runx2 3'UTR carrying a putative miR-196b-binding site into pMiR-report vector (Promega, Madison, WI, USA) were amplified by PCR. Cells were co-transfected with the reporter construct, control vector and miR-196b mimic or mimic control using Lipofectamine 3000 (Life Technologies). Reporter assays were done using the dual-luciferase assay system (Promega) following to the manufacturer's information.

\section{Western blot}

The protein used for western blot was extracted using radio immunoprecipitation assay (RIPA) lysis buffer (Beyotime Biotechnology, Shanghai, China) supplemented with protease inhibitors (Roche, Basle, Switzerland). The concentrations of protein extracts were quantified using the $\mathrm{BCA}^{\mathrm{TM}}$ Protein Assay Kit (Pierce, Appleton, WI, USA). The western blot system was established using a Bio-Rad Bis-Tris Gel system according to the manufacturer's instructions. Primary antibodies were prepared in 5\% blocking buffer 


\section{Cellular Physiology Cell Physiol Biochem 2017;43:757-767 \begin{tabular}{ll|l} 
and Biochemistry & $\begin{array}{l}\text { DOI: 10.1159/000481559 } \\
\text { Published onllne: September 27, } 2017\end{array}$ & $\begin{array}{l}\text { @ } 2017 \text { The Author(s). Published by S. Karger AG, Basel } \\
\text { www.karger.com/cpb }\end{array}$ \\
\hline
\end{tabular} \\ Bai et al.: Role of Mir-196b in Lung Cancer by Targeting Runx2}

at a dilution of $1: 1,000$ and were incubated with the membranes at $4^{\circ} \mathrm{C}$ overnight. Thereafter, the membranes were washed and incubated with secondary antibody (dilution of 1:5000) marked by horseradish peroxidase for $1 \mathrm{~h}$ at room temperature. After rinsing, the polyvinylidene difluoride (PVDF) membranes (Millipore, Bedford, MA, USA) carried blots and antibodies were transferred into the Bio-Rad ChemiDoc ${ }^{\mathrm{TM}}$ XRS system. The immunoreactive protein bands were visualized using chemiluminescence (PerkinElmer, Wellesley, MA, USA).

\section{Statistical analysis}

All experiments were repeated three times. The results of multiple experiments are presented as mean \pm standard derivations (SD). Statistical analyses were performed using SPSS 19.0 statistical software (SPSS Inc., Chicago, IL). The $P$-values were calculated using one-way analysis of variance (ANOVA). A $P$-value of $<$ 0.05 was considered to indicate a statistically significant result.

\section{Results}

MiR-196b was low expressed in different lung cancer cells

The expression levels of miR-196b were assessed in different cell lines of lung cancer cell lines A549, H1650 and H1299 and human normal lung cell lines WI-38 and HEL-1 by qRT-PCR. All the lung cancer cell lines revealed reduced expression levels of miR-196b compared to human lung cell lines $(P<0.01$ or $P<0.001$, Fig. 1$)$. The expression level was maximally reduced in the A549 lung cancer cell line, hence A549 cell line was chosen in the following experiments.

MiR-196b suppressed cell viability, migration, invasion, and induced apoptosis

To assess the role of miR-196b in cell viability, migration, invasion, and apoptosis, A549 cells were transfected with miR-196b mimic, miR-196b inhibitor and corresponding controls. Results showed that the expression level of miR-196b was significantly up-regulated by miR-196b mimic and down-regulated by miR-196b inhibitor $(P<0.01$ or $P<0.001$, Fig. $2 A)$. In terms of cell viability, migration and invasion, miR-196b overexpression remarkably decreased cells viability, migration and invasion in A549 cells compared to its control group $(P<0.05)$. At same time, these effects were reversed by miR-196b suppression $(P<0.05$, Fig. 2B-2D).

In terms of cell apoptosis, the percentage of apoptotic cells was significantly enhanced by miR-196b overexpression compared to control $(P<0.001$, Fig. 2E). There was no obviously effect of miR-196b suppression on cell apoptosis. Meanwhile, the western blot results revealed that miR-196b overexpression down-regulated Bcl-2 expression, up-regulated Bax expression as well as activated cleaved-caspase- 3 and cleaved-caspase-9 expressions. MiR196b suppression showed an opposite results of Bcl-2 and Bax expressions. There were no obviously changes of pro-caspase-3 and pro-caspase-9 (Fig. 2F). Taken together, these data indicated that miR-196b inhibited cell growth and metastasis of A549 cells.

MiR-196b suppressed EMT process in $A 549$ cells

To explore the effect of miR-196b on EMT process, A549 cells were transfected with miR-196b mimic, miR-196b inhibitor and corresponding controls. After inducing by $10 \mathrm{ng} / \mathrm{ml}$ of KARGER
Fig. 1. MiR-196b was low expressed in lung cancer cell lines. MiR-196b was significantly down-regulated in lung cancer cell lines (A549, H-1650 and H-1299) compared to normal lung cell lines (WI-38, HEL-1). MiR196b: microRNA-196b; **, $\mathrm{P}<0.01$; $* * *, \mathrm{P}<0.001$ when compared with WI-38 cell line; \#\#, $\mathrm{P}<0.01$; \#\#\#, $\mathrm{P}<0.001$ when compared with HEL-1 cell line.

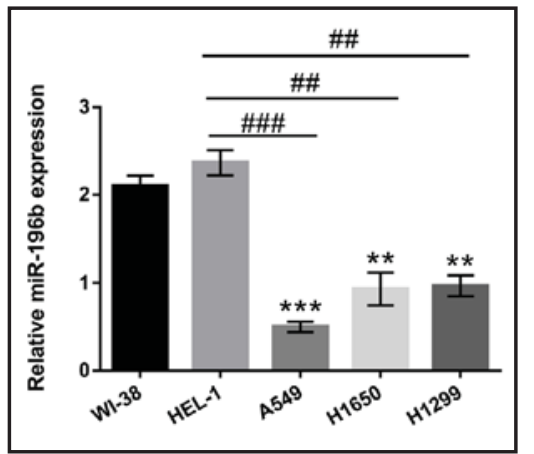




\section{Cellular Physiology Cell Physiol Biochem 2017;43:757-767

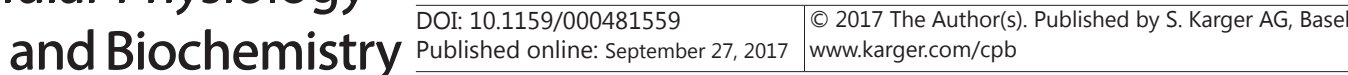

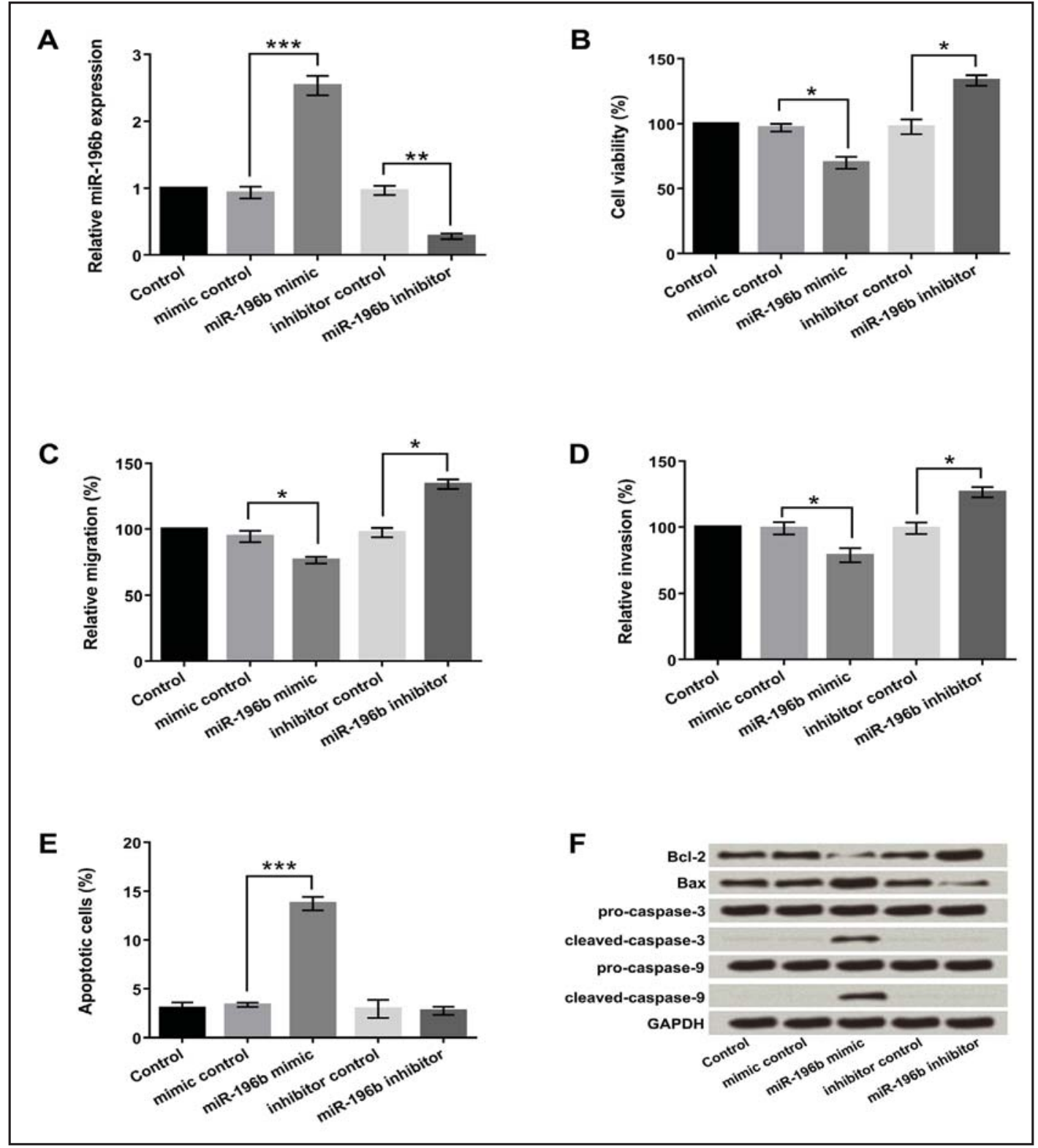

Fig. 2. MiR-196b inhibited cell viability, migration, invasion, and promoted apoptosis. A549 cells were transfected with miR-196b mimic, mimic control, miR-196b inhibitor and inhibitor control. A: MiR-196b expression was up-regulated in miR-196b mimic transfected cells but down-regulated in miR-196b inhibitor transfected cells; B-D: Overexpression of miR-196b inhibited cell viability, migration and invasion, but suppression of miR-196b promoted cell viability, migration and invasion in A549 cells; E: Overexpression of miR-196b promoted cell apoptosis in A549 cells; F: Overexpression of miR-196b promoted apoptosis-related proteins expressions, and suppression of miR-196b inhibited apoptosis-related proteins expressions in A549 cells. MiR-196b: microRNA-196b; *, P<0.05; **, $\mathrm{P}<0.01$; ***, $\mathrm{P}<0.001$.

TGF- $\beta 1$, the protein levels of EMT-related factors were detected by western blot. As results revealed in Fig. 3, miR-196b overexpression promoted E-cadherin expression but inhibited $\mathrm{N}$-cadherin, Vimentin, ZEB1, and Snail expressions. Of contrast, miR-196b suppression led to opposite results for these five factors expressions. These results demonstrated that miR$196 \mathrm{~b}$ could suppress EMT process. 


\section{Cellular Physiology Cell Physiol Biochem 2017;43:757-767 \begin{tabular}{ll|l} 
and Biochemistry $10.1159 / 000481559$ & $\begin{array}{l}\text { O 2017 The Author(s). Published by S. Karger AG, Basel } \\
\text { www.karger.com/cpb }\end{array}$ \\
\hline
\end{tabular} \\ Bai et al.: Role of Mir-196b in Lung Cancer by Targeting Runx2}

Fig. 3. MiR-196b inhibited EMT process. A549 cells were transfected with miR-196b mimic, miR-196b inhibitor and corresponding controls and then induced by $10 \mathrm{ng} / \mathrm{ml}$ of TGF- $\beta 1$. Overexpression of miR-196b promoted E-cadherin expression but inhibited $\mathrm{N}$-cadherin, $\mathrm{Vi}$ mentin, ZEB1 and Snail expressions.MiR-196b: microRNA-196b; EMT: epithelial-mesenchymal transition; TGF- $\beta 1$ : transforming growth factor-beta 1; ZEB1: zinc-finger E-box binding homeobox 1.

Fig. 4. Runx2 was a target of miR-196b. A: miR-196b negatively regulated the mRNA and protein expressions of Runx2 in A549 cells; B: Runx2 was a target of miR-196b in A549 cells. Runx2: Runt-related transcription factor 2; MiR-196b: microRNA-196b; *, P<0.05; **, $\mathrm{P}<0.01$.

\section{Runx2 was a target of miR-196b}

To explore the relationship between miR196b and Runx2, A549 cells were transfected with miR-196b mimic, miR-196b inhibitor and corresponding controls. qRT-PCR and western blot assays were used to examined the mRNA and protein levels of Runx2 in different experiment groups. The results displayed that the mRNA expression of Runx2 were signally down-regulated by miR-196b overexpression but up-regulated by miR-196a suppression compared to corresponding controls $(P<$ 0.05 or $P<0.01$ ). Western blot analysis with a similar trend to mRNA level of Runx2 (Fig. 4A).

Further, dual luciferase activity assay was performed to verify whether miR-196b was able to directly bind to its site sequences in the Runx2 3'-UTR in A549 cells; Runx2-wt and Runx2-mt containing the wild-type and mutant binding sequences of miR-196b within the 3'-UTR of Runx2 mRNA were generated. Results showed that miR-196b overexpression reduced the activity of luciferase reporter fused to the Runx2-wt $(P<0.01)$. However, there was no significant difference in A549 cells co-transfected with Runx2-mt when compared with the control group (Fig. 4B). Overall, these data indicated that miR-196b inhibited Runx2 expression by directly targeting its 3'-UTR.

MiR-196b inhibited cell viability, migration and invasion and promoted apoptosis by regulation of Runx 2

To explore the effects of miR-196b and Runx2 on cell viability, migration, invasion and apoptosis, miR-196b inhibitor, miR-196b inhibitor + si-Runx2 and corresponding control were transfected into A549 cells. Results revealed in Fig. 5A, miR-196b inhibitor + si-Runx2 prominently reduced Runx2 expression compared to miR-196b inhibitor group. Then miR$196 \mathrm{~b}$ suppression significantly elevated cell viability, migration and invasion compared to inhibitor control group $(P<0.05)$. While the promoting effects of miR-196b suppression on cell viability, migration and invasion were abolished by miR-196b inhibitor + si-Runx2 $(P<$ 


\section{\begin{tabular}{ll} 
Cellular Physiology & Cell Physiol Biochem 2017;43:757-767 \\
\cline { 2 - 3 } DOI: 10.1159/000481559 & O 2017 The Author(s). Published by S. Karger AG, Basel
\end{tabular} and Biochemistry Published online: September 27, 2017 www.karger.com/cpb

A

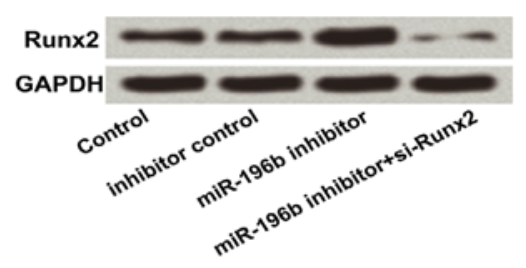

C

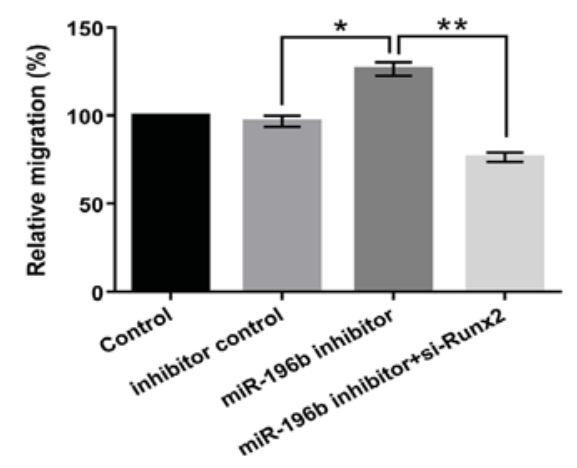

E

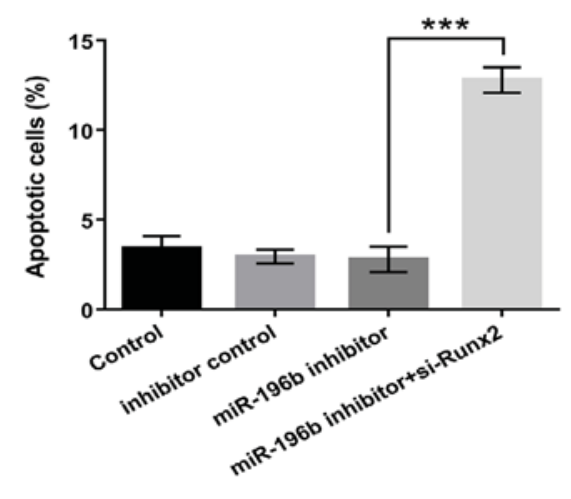

B

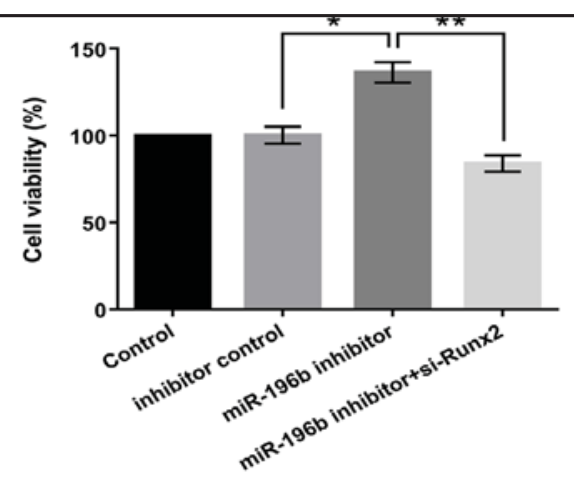

D

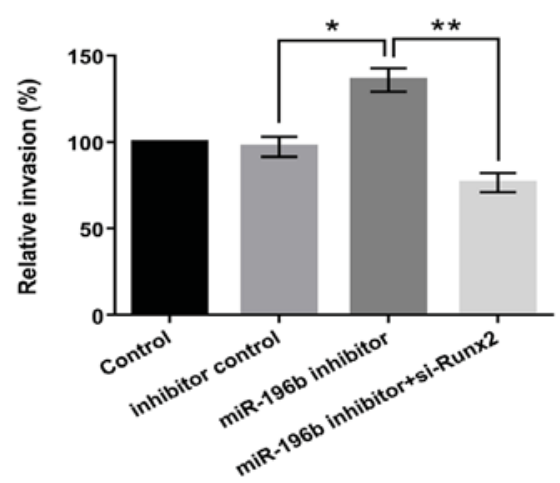

$\mathbf{F}$

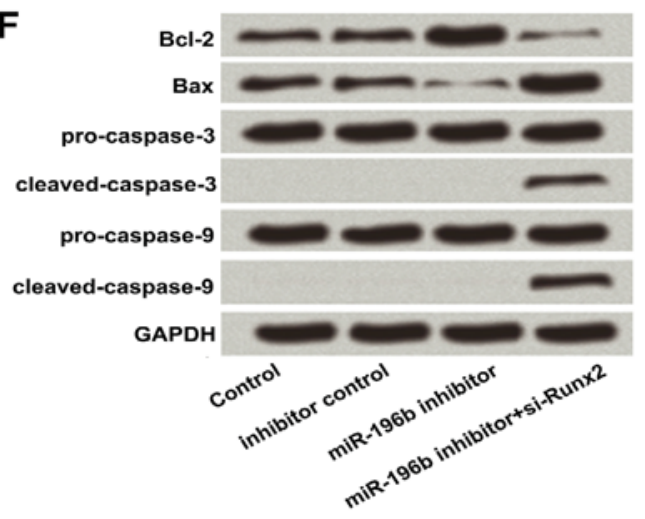

Fig. 5. MiR-196b inhibited cell viability, migration, invasion and promoted apoptosis in A549 cells by regulation of Runx2. MiR-196b inhibitor or/and Runx2 siRNA were transfected into A549 cells. A: Suppression of miR-196b increased Runx2 expression, and co-transfected with miR-196b inhibitor and Runx2 siRNA decreased Runx2 expression in A549 cells; B-D: Suppression of miR-196b promoted cell viability, migration and invasion, while co-transfected with miR-196b inhibitor and Runx2 siRNA inhibited cell viability, migration and invasion in A549 cells; E: Co-transfected with miR-196b inhibitor and Runx2 siRNA promoted cell apoptosis in A549 cells; F: Suppression of miR-196b promoted cell apoptosis-related proteins expressions, and co-transfected with miR-196b inhibitor and Runx2 siRNA inhibited the cell apoptosis-related proteins expressions in A549 cells.MiR-196b: microRNA-196b; Runx2: Runt-related transcription factor 2; ${ }^{*}, \mathrm{P}<0.05$; **, $\mathrm{P}<0.01 ; * * *, \mathrm{P}<0.001$.

0.01, Fig. 5B-5D). Furthermore, miR-196b inhibitor + si-Runx2 remarkably promoted cell apoptosis compared to miR-196 inhibitor group $(P<0.001$, Fig. 5E). Moreover, western blot results showed that miR-196b inhibitor + si-Runx2 inhibited Bcl-2 expression, promoted Bax 


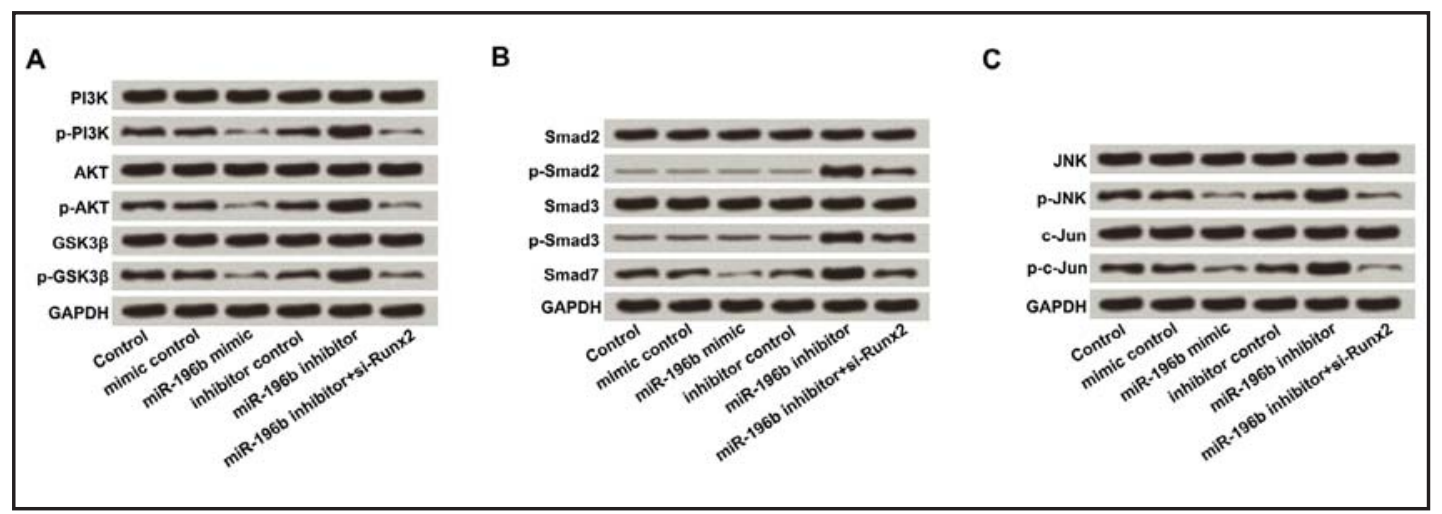

Fig. 6. MiR-196b inactivated PI3K/AKT/GSK3 $\beta$, Smad, and JNK pathways by regulation of Runx2. A: Overexpression of miR-196b inactivated PI3K/AKT/GSK3 $\beta$ pathway in A549 cells; B: Overexpression of miR-196b inactivated Smad pathway in A549 cells; C: Overexpression of miR-196b inactivated JNK pathway in A549 cells. MiR-196b: microRNA-196b; Runx2: Runt-related transcription factor 2; PI3K: phosphoinositide-3-Kinase; AKT: protein kinase B; GSK3ß: glycogen synthase kinase 3 beta; JNK: Jun N-terminal kinases.

expression and activated cleaved-caspase- 3 and cleaved-caspase- 9 expressions compared to miR-196b suppression group. There were no obviously changes of pro-caspase- 3 and procaspase-9 (Fig. 5F). In a word, these data indicated that Runx2 silence induced apoptosis and abolished the promotive effects of miR-196b suppression on cell viability, migration and invasion.

MiR-196b blocked PI3K/AKT/GSK3 $\beta$, Smad, and JNK pathways by regulation of Runx2

To explore the role of miR-196b and Runx2 in PI3K/AKT/GSK3 $\beta$, Smad, and JNK signal pathways, A549 cells were transfected with miR-196b mimic, miR-196b inhibitor, miR-196b inhibitor + si-Runx2 and corresponding controls. Results showed in Fig. 6A-6C, the three signal pathways key factors of p-PI3K, p-AKT, p-GSK3 $\beta$, p-Smad2, p-Smad3, Smad7, p-JNK and p-c-Jun were significantly down-regulated by miR-196b overexpression, as well as upregulated by miR-196b suppression. While miR-196b inhibitor + si-Runx2 abolished the activation effects of miR-196b suppression on these eight factors. There were no obviously changes of PI3K, AKT, GSK3 $\beta$, Smad2, Smad3, JNK and c-Jun. These data indicated that miR196b could block PI3K/AKT/GSK3 $\beta$, Smad, and JNK pathways by regulation of Runx2.

\section{Discussion}

In the present study, we explored the role of miR-196b in lung cancer cells. It demonstrated that miR-196b was low expressed in lung cancer cells. MiR-196 overexpression significantly inhibited cell viability, migration and invasion and promoted apoptosis of A549 cells. In addition, we also found that Runx2 was a direct target of miR-196b, and Runx2 silence significantly induced apoptosis and abolished the promotive effects of miR-196b suppression on cell viability, migration and invasion. Furthermore, miR-196b blocked PI3K/ AKT/GSK3 $\beta$, Smad, and JNK pathways by regulation of Runx2.

Several studies have demonstrated that abnormal expressions of miRNAs have been found in lung cancer, and some of these miRNAs are involved in modulating lung cancer cells proliferation, metastasis and apoptosis $[24,25]$. As Chen et al. demonstrated that the expression level of miR-144 was increased in lung cancer cells and up-regulation of miR144 could suppress lung cancer cells proliferation, induce apoptosis and autophagy [26]. In addition, Bhatia et al. uncovered the tumor suppressor role of miR-196b in B-cell lineage acute lymphoblastic leukemia via promoting cell apoptosis in EB-3 cells [27]. Similar to 


\section{Cellular Physiology Cell Physiol Biochem 2017;43:757-767

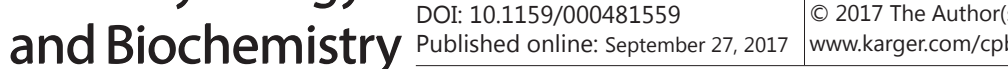 \\ Bai et al.: Role of Mir-196b in Lung Cancer by Targeting Runx2}

previous studies, our study demonstrated that miR-196b was significantly decreased in lung cancer cells and miR-196b acted as a tumor suppressor that inhibited lung cancer cells growth and metastasis.

It is generally known that EMT is a biological phenomenon in which the epithelial cells lose their characteristic cellular properties and acquire those of mesenchymal cells [28]. It is associated with a number of physiological processes like wound healing, invasion and metastasis [29]. Recent studies have proved that miRNAs play a key role in induction EMT $[30,31]$. Here, we have demonstrated the inhibitory effects of miR-196b on EMT in lung cancer cells. Similar to our finding, Ma et al. revealed that miR-124 as a tumor suppressor that suppressed EMT process in NSCLC [25]. Whereas, in contrast to our finding, Liao et al. demonstrated that miR-196b promoted EMT process, through decreasing E-cadherin expression and increasing N-cadherin, Vimentin, ZEB1, and Snail expressions in gastric cancer cells [32]. The opposite reason may be due to the difference functions of miR-196b in diverse tumor cells. However, further study need to clarify this hypothesis.

Runx2 is a transcription factor, which is recognized that its regulation activities are associated with increased cell growth, invasion and metastasis in various tumor types [33]. Previous studies have confirmed that the role of Runx2 as proto-oncogene in lung cancer $[21,22]$. Moreover, Xie et al. demonstrated that Runx2 was a direct and functional target of miR-218, and Runx2 could execute the former on lung cancer chemo-resistance [34]. Therefore, we supposed whether Runx2 was a target of miR-196b and involved in regulation of lung cancer cells cellular functions. Just as we expected, our study confirmed that Runx2 was a direct target gene of miR-196b and was negatively regulated by miR-196b. Moreover, we also found that Runx 2 silence could induce apoptosis and abolish the promotive effects of miR-196b suppression on cell viability, migration and invasion. Thus, the data suggested that miR-196b inhibited cell growth and metastasis by targeting Runx2. Similar to our findings, Zheng et al. have demonstrated that WW domain-containing oxidoreductase (WWOX), which is a tumor suppressor, suppressed the invasiveness of lung cancer cells via regualtion of Runx2 expression [20].

Mounting evidences confirmed the beneficial role of suppression of PI3K/AKT/GSK3 $\beta$, Smad, and JNK pathways in various cancers [35-37]. As Li et al. reported that miR-196b improved cell proliferation and invasion ability by regulating of PI3K/AKT/mTOR signal pathway in gastric cancer cells [38]. Furthermore, Manish et al found that Runx2 could regulate PI3K/AKT pathway and play a pivotal role in modulating breast cancer-associated cell survival and invasive properties [39]. However, the cross-regulation between miR-196b and Runx2 in PI3K/AKT/GSK3 $\beta$, Smad, and JNK signal pathways remains unclear. In this study, we found that miR-196b suppression activated PI3K/AKT/GSK3 $\beta$, Smad, and JNK pathways. However, the activation effects were abolished by Runx2 silence. These data indicated that miR-196b could block PI3K/AKT/GSK3 $\beta$, Smad, and JNK pathways through regulation of Runx2 expression in A549 cells.

Collectively, our study demonstrated that miR-196b as a tumor suppressor that inhibited lung cancer cells growth, metastasis and blocked PI3K/AKT/GSK3ß, Smad, and JNK pathways by targeting Runx2. These findings suggested that miR-196b might be considered as a novel drug target in the treatment of lung cancer.

\section{Disclosure Statement}

None declared.

\section{References}

1 Yu SL, Lee DC, Sohn HA, Lee SY, Jeon HS, Lee JH, Park CG, Lee HY, Yeom YI, Son JW: Homeobox A9 directly targeted by miR-196b regulates aggressiveness through nuclear Factor-kappa B activity in non-small cell lung cancer cells. Mol Carcinogen 2015;55:1915-1926. 


\section{Cellular Physiology Cell Physiol Biochem 2017;43:757-767

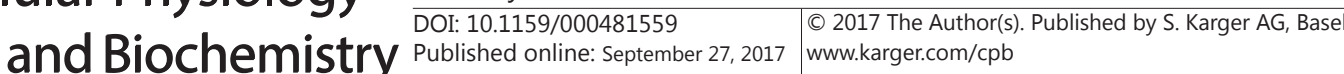

Bai et al.: Role of Mir-196b in Lung Cancer by Targeting Runx2

-2 Li X, Shi Y, Yin Z, Xue X, Zhou B: An eight-miRNA signature as a potential biomarker for predicting survival in lung adenocarcinoma. J Transl Med 2014;12:159.

3 Maasdorp SD, Snyman CE, Prins M, Rooyen FCV, Struwig MC: Clinical profile of patients diagnosed with primary lung cancer at the Pulmonology Division, Universitas Academic Hospital, Bloemfontein, 20102011. South Afr J Epidemiol Infect 2013;233-239.

4 Barger JF, Nanasinkam SP: MicroRNA as tools and therapeutics in lung cancer. Resp Med 2015;109:803.

5 Rusek A, Abba M, Eljaszewicz A, Moniuszko M, Niklinski J, Allgayer H: MicroRNA modulators of epigenetic regulation, the tumor microenvironment and the immune system in lung cancer. Mol Cancer 2015;14:34.

6 Ortholan C, Puissegur MP, Ilie M, Barbry P, Mari B, Hofman P: MicroRNAs and lung cancer: new oncogenes and tumor suppressors, new prognostic factors and potential therapeutic targets. Curr Med Chem 2009;16:1047-1061.

7 Huang C, Ma R, Yue J, Li N, Li Z, Qi D: MiR-497 Suppresses YAP1 and Inhibits Tumor Growth in Non-Small Cell Lung Cancer. Cell Physiol Biochem 2015;37:342-352.

8 Tsai LM, Yu D: MicroRNAs in common diseases and potential therapeutic applications. Clin Exp Pharmacol Physiol 2010;37:102-107.

9 Yan A, Yang C, Chen Z, Li C, Cai L: MiR-761 Promotes Progression and Metastasis of Non-Small Cell Lung Cancer by Targeting ING4 and TIMP2. Cell Physiol Biochem 2015;37:55-66.

10 Jiang X, Men W, Zhang L, Liu H, Li W: The effects of miRNA21 on the proliferation and migration of human lung cancer cell line A549 cells. Journal of Modern Oncology 2016;

11 Zhang B, Pan X, Cobb GP, Anderson TA: RNAs as oncogenes and tumor suppressors. Dev Biol Dev Biol 2007;302:1-12.

12 Chen C, Zhang Y, Zhang L, Weakley SM, Yao Q: MicroRNA-196: critical roles and clinical applications in development and cancer. IEEE T Neural Networks 2011;15:14-23.

13 Rebucci M, Sermeus A, Leonard E, Delaive E, Dieu M, Fransolet M, Arnould T, Michiels C: miRNA-196b inhibits cell proliferation and induces apoptosis in HepG2 cells by targeting IGF2BP1. Mol Cancer 2015;14:79.

14 Bhatia S, Kaul D, Varma N: Potential tumor suppressive function of miR-196b in B-cell lineage acute lymphoblastic leukemia. Mol Cell Biochem 2010;340:97-106.

15 Bhatia S, Kaul D, Varma N: Functional genomics of tumor suppressor miR-196b in T-cell acute lymphoblastic leukemia. Mol Cell Biochem 2011;346:103-116.

$\checkmark 16$ Ji WS, Yu SL, Dong CL, Lee SY, Chang GP, Lee HY, Kang J: Abstract 4353: microRNA-196b induces epithelialto-mesenchymal transition through targeting HOXA9 in non-small cell lung cancer cells. Cancer Res 2014; 74:4353-4353.

17 Tellez CS, Juri DE, Do K, Picchi MA, Wang T, Liu G, Spira A, Belinsky SA: miR-196b Is Epigenetically Silenced during the Premalignant Stage of Lung Carcinogenesis. Cancer Res 2016;76:4741.

$\longrightarrow 18$ Wysokinski D, Blasiak J, Pawlowska E: Role of RUNX2 in Breast Carcinogenesis. Int J Mol Sci 2015;16:20969-20993.

19 Li N, Luo D, Hu X, Luo W, Lei G, Wang Q, Zhu T, Gu J, Lu Y, Zheng Q: RUNX2 and Osteosarcoma. Anti-cancer Agent Med Chem 2015;15:881.

20 Zheng QW, Zhou YL, You QJ, Shou F, Pang QF, Chen JL: WWOX inhibits the invasion of lung cancer cells by downregulating RUNX2. Cancer Gene Ther 2016;23:433.

21 Hsu YL, Huang MS, Yang CJ, Hung JY, Wu LY, Kuo PL: Lung tumor-associated osteoblast-derived bone morphogenetic protein-2 increased epithelial-to-mesenchymal transition of cancer by Runx2/Snail signaling pathway. J Biol Chem 2011;286:37335-37346.

22 Tandon M, Gokul K, Ali SA, Chen Z, Lian J, Stein GS, Pratap J: Runx2 mediates epigenetic silencing of the bone morphogenetic protein-3B (BMP-3B/GDF10) in lung cancer cells. Mol Cancer 2012;11:27.

-23 Rice SJ, Lai SC, Wood LW, Helsley KR, Runkle EA, Winslow MM, Mu D: MicroRNA-33a mediates the regulation of high mobility group AT-hook 2 gene (HMGA2) by thyroid transcription factor 1 (TTF-1/NKX21). J Biol Chem 2013;288:16348-16360.

24 Feng S, Cong S, Zhang X, Bao X, Wang W, Li H, Wang Z, Wang G, Xu J, Du B: MicroRNA-192 targeting retinoblastoma 1 inhibits cell proliferation and induces cell apoptosis in lung cancer cells. Nucleic Acids Res 2011;39:6669-6678. 


\section{Cellular Physiology Cell Physiol Biochem 2017;43:757-767

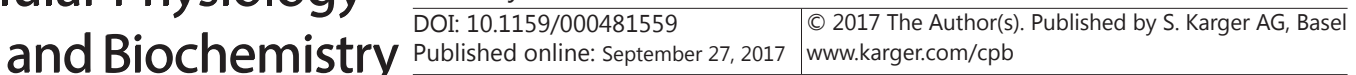

Bai et al.: Role of Mir-196b in Lung Cancer by Targeting Runx2

25 Ma T, Zhao Y, Wei K, Yao G, Pan C, Liu B, Xia Y, He Z, Qi X, Li Z: MicroRNA-124 Functions as a Tumor Suppressor by Regulating CDH2 and Epithelial-Mesenchymal Transition in Non-Small Cell Lung Cancer. Cell Physiol Biochem 2016;38:1563.

-26 Chen S, Li P, Li J, Wang Y, Du Y, Chen X, Zang W, Wang H, Chu H, Zhao G: MiR-144 Inhibits Proliferation and Induces Apoptosis and Autophagy in Lung Cancer Cells by Targeting TIGAR. Cell Physiol Biochem 2015;35:997-1007.

27 Bhatia S, Kaul D, Varma N: Functional genomics of tumor suppressor miR-196b in T-cell acute lymphoblastic leukemia. Mol Cell Biochem 2011;346:103.

28 Christiansen JJ, Rajasekaran AK: Reassessing epithelial to mesenchymal transition as a prerequisite for carcinoma invasion and metastasis. Cancer Res 2006;66:8319-8326.

-29 Chen T, You Y, Jiang H, Wang ZZ: Epithelial-mesenchymal transition (EMT): A biological process in the development, stem cell differentiation, and tumorigenesis. J Cell Physiol 2017;

-30 Kothari AN, Mi Z, Zapf M, Kuo PC: Novel clinical therapeutics targeting the epithelial to mesenchymal transition. Clin Transl Med 2014;3:35.

-31 Liu Z, Jin ZY, Liu CH, Xie F, Lin XS, Huang Q: MicroRNA-21 regulates biological behavior by inducing EMT in human cholangiocarcinoma. Int J Clin Exp Pathol 2015;8:4684.

-32 Liao YL, Hu LY, Tsai KW, Wu CW, Chan WC, Li SC, Lai CH, Ho MR, Fang WL, Huang KH: Transcriptional regulation of miR-196b by ETS2 in gastric cancer cells. Carcinogenesis 2012;33:760-769.

33 Browne, Gillian: The role of the Runx2 in apoptosis resistance in hormone sensitive breast and prostate cancer cells, University of Ulster, 2010.

-34 Xie J, Yu F, Li D, Zhu X, Zhang X, Lv Z: MicroRNA-218 regulates cisplatin (DPP) chemosensitivity in nonsmall cell lung cancer by targeting RUNX2. Tumor Biol 2016;37:1197-1204.

-35 Fumarola C, Bonelli MA, Petronini PG, Alfieri RR: Targeting PI3K/AKT/mTOR pathway in non small cell lung cancer. Biochem Pharmacol 2014;90:197-207.

-36 Jeon HS, Jin J: TGF- $\beta$ Signaling and the Role of Inhibitory Smads in Non-small Cell Lung Cancer. J Thorac Oncol 2010;5:417-419.

37 Bubici C, Papa S: JNK signalling in cancer: in need of new, smarter therapeutic targets. Brit J Pharmacol 2014;171:24-37.

-38 Li N, Wang W, Xu B, Gong H: miR-196b regulates gastric cancer cell proliferation and invasion via PI3K/ AKT/mTOR signaling pathway. Oncol Lett 2016;11:1745-1749.

-39 Tandon M, Chen Z, Pratap J: Abstract 3081: Crosstalk between Runx2 regulatory network and PI3K/Akt signaling pathway in breast cancer cells. Cancer Res 2012;72:3081-3081. 